\title{
Student perspectives on their engagement with a mathematics support centre website
}

\author{
Ciarán Mac an Bhaird, Department of Mathematics and Statistics, Maynooth University, Ireland. \\ Email: ciaran.macanbhaird@mu.ie \\ Peter Mulligan, Department of Mathematics and Statistics, Maynooth University, Ireland. \\ Email: peter.mulligan@mu.ie \\ James O'Malley, Department of Mathematics and Statistics, Maynooth University, Ireland. \\ Email: james.omalley@mu.ie
}

\begin{abstract}
In this paper, we focus on survey results of students' use of a Mathematics Support Centre website. We discuss potential modifications to the advertisement of our online services based on student responses. We also consider the purpose of an MSC website and who should be responsible, in an institution, for the provision of topic specific online resources for students.
\end{abstract}

Keywords: Mathematics support, website, online, resources.

\section{Introduction and background}

The Mathematics Support Centre (MSC) was established by the Department of Mathematics and Statistics (the Department) in Maynooth University (MU) in 2007. Its remit, similar to that of most MSCs (Lawson et al., 2012), was to tackle retention issues, especially in first year service mathematics courses. The majority of MSC attendees take service mathematics and there is also a small class of pre-degree Certificate students. However, it is not just 'at-risk' first years who avail of MSC services. In MU (Mac an Bhaird et al., 2009) and elsewhere (Grove et al., 2019), students with stronger mathematical backgrounds also attend MSCs to improve their grades.

In 2007, appropriate advertisement was identified as crucial to raise awareness of our MSC amongst undergraduates. One approach advised by colleagues, both in person and through publications (Lawson et al., 2003; Mac an Bhaird and Lawson, 2012), was the establishment of an online presence. Initially, based on online reviews of MSCs in other institutions, we had a webpage with information on opening hours, venue, and a brief description of what students should expect in the MSC. As the MSC became firmly established, the webpage became a website in 2009, which contained similar information but presented in a more coherent fashion. The main MSC services at MU were (and still are) drop-in and weekly workshops. All workshops were held in the MSC and were optional. They focus on specific material requested by students from their modules; the material could not be due on a subsequent module assignment and was subject to lecturer approval. Each first year workshop had a dedicated page on MU's virtual learning environment (VLE) where workshop notes were placed along with links to related online materials. For other on-demand workshops for non-first years, notes were placed on a dedicated MSC webpage for one week only due to Department instructions. We also added a page for online resources, which similar to other MSC websites, linked to locally developed resources and online repositories, e.g. www.mathcentre.ac.uk. Over a subsequent four-year period, the website saw mostly ad hoc changes, including moving servers due to changing internal university policies. While the impact of institutional procedures and policies on MSC websites appears relatively common, the fact that we retained control of editing and content is less common (Mac an Bhaird et al., in preparation).

Anecdotal feedback during this period identified that students were rarely accessing resources on our website, as they did not see how they related to their modules. We decided to change both the 
layout and extent of online resources in summer 2013. A tutor gathered online materials relevant to the main 1st and 2nd year modules in the Department, single and multivariable Calculus, Linear Algebra, Data Analysis and Statistics. The selected material, usually in video or text format, was reviewed to ensure academic accuracy and placed on a topic webpage. In keeping with the MSC's ethos as a supplement to, not a replacement for, Departmental course material, there is a statement to that effect on each topic webpage. We did not focus on materials for 3rd and 4th year modules as they tend to be more advanced in nature, with content often changing depending on the lecturer. Our current website (http://supportcentre.maths.nuim.ie) has changed little since 2013, the only significant changes of note have been the addition of our Twitter and Facebook feeds to the main page.

Key to the success of MLS is that best practice is based on informed research. In MU, research priority was given to the potential impact of our drop-in service (27 hours per week) on the retention of students (Mac an Bhaird et al., 2009; Berry et al., 2015). This is a common area of MLS research (Matthews et al., 2013). We had never evaluated our website and in early 2018, the possibility arose that control of the structure and layout of the MSC website might go to staff outside the Department. A review of literature in MLS and related fields identified that, to the best of our knowledge, very little work had been carried out in this area. Indeed, recent reports recommended that steps be taken to address this, for example

"Further investigation be undertaken to explore how MLS providers can enhance the online resources and services available to students, and increase student awareness of and improve student accessibility to these ICT enabled Supports." (O'Sullivan et al., 2014, p.83)

We decided to investigate student use of our website and, to provide a broader context, we also conducted a survey of MLS practitioners in Ireland and the UK on the extent of their online MLS presence. The results of that survey are available in Mac an Bhaird et al. (in preparation). In this paper, we briefly describe our methodology and subsequently focus on the results of the student survey. We close with a discussion based on the results and consider potential next steps.

\section{Methodology}

In March 2018, the authors developed a survey hosted on Google forms. The focus, comprising of 14 survey items, was to try to establish whether MU students used the MSC website, why they did or did not engage, whether or not they used online resources on the MSC website and the reasons why. We added 13 extra questions on background and on student use of online resources in general. These are reported on in Mac an Bhaird et al. (2020a). The anonymous survey was trialled by MSC tutors. The structure was subsequently altered and some of the questions were reworded.

Ethical approval was received for the final survey and, in April 2018, the survey was placed on the VLE page for all Department students who also received an email inviting them to participate. MSC attendees were also made aware of the survey and invited to participate. There were 99 respondents in total, and the results were downloaded to SPSS (Version 24) and analysed. Any responses to open questions were coded separately by the authors, who subsequently met and finalised categories of response.

\section{Results}

All respondents $(n=99)$ were asked if they had ever used the MSC website (Q1), with 68 selecting that they had, 15 that they had not, and 16 that they did not know the MSC had a website. The majority of those who answered no (11 of 15) and all who did not know about the MSC website were Certificate, 1 st or 2 nd year students. 


\subsection{Students who have not used or did not know about the MSC website ( $n=31)$}

Respondents were asked, in an open response question (Q2), why they had not used the website. The 16 students (from Q1) who did not know about the website repeated this fact. Twelve of the remaining 15 respondents gave relevant comments. The most common response $(n=7)$ was that students did not need it, with some adding extra details such as 'have my notes', 'I usually just get help in the MSC', 'I prefer to get hands on assistance'. Four further comments referred to a lack of continuous visibility or advertisement of the website, e.g., 'It was only mentioned to us during our first week; l'd actually forgotten there was a site'. The remaining response raised broader orientation issues:

"As a mature student I rely on traditional study methods and am very backward when it comes to technology. I don't understand its potential. I just don't know or understand how it might be helpful to me. I'm very surprised that the university didn't alert people like me beforehand about the extent of the use of technology in student life today. If it had I would have tried to get into it a bit." (1st Year student)

In another open response question (Q3), respondents were asked what would encourage them to start using the website. Twenty (of 31 ) students gave relevant responses. Nine comments related to how they thought the website should be advertised, including advice on how to communicate the information to students 'A link/ advertisement, as well as promotion by MSC staff' and suggestions on information to include in the advertisement 'helpful notes on topics we are dealing with such as at the moment linear algebra'. Eight said 'if they had known about it', with five of these specifying that 'Now that I know it exists, I will use it'. The remaining three comments were 'more time', 'an online chat with a support', and 'not being able to make it into college'.

\subsection{Students who have used the MSC website ( $n=68$ )}

Respondents who have used the MSC website were asked to select what they used the MSC Website for (Q4), with fixed options 'To find out MSC opening hours' (63), 'To find out when a particular tutor is on' (44), 'To find out what topics each tutor is comfortable with' (31), 'To find MSC contact details' (6). There were 151 responses, including 7 open response answers all of which related to accessing resources, e.g. 'List of additional resources/websites on maths', 'notes from workshops'. Of the 7 students who gave an open response, only one had not selected any of the fixed options. This indicates that 67 of the 68 students were using the MSC website for information purposes. Third and 4th years were the most common groups to use the MSC website to find out when a particular tutor was on duty (34 of 44 ) and to find what topics a tutor is comfortable with (25 of 31$)$.

Thirty (of 68) students indicated (Q5) that they used online resources on the MSC website, and 38 that they did not.

\subsubsection{Students who have used the MSC website but not the MSC online resources ( $n=38$ )}

Respondents who have used the MSC website were asked why they did not use online resources on the MSC website (Q6), with fixed options 'I did not think of them' $(n=20)$; 'I did not know they were there' ( $n=14)$; 'I find it too difficult to find what I am looking for' $(n=8)$; 'I do not think that the online resources that are there are helpful' $(n=6)$. There were 48 responses, including three open responses answers 'I usually have a specific question and that's why I come to the msc. I prefer one on one' (2nd Science), 'No relevant information for modules (4th Science)', and 'I try to stick to the lecturer's notes' (3rd Arts).

These respondents were asked, in an open response question (Q7), what would encourage them to use the online resources. Thirty-four (of 38) responses were relevant to the evaluation of the MSC website. Seventeen comments referred to the resource content of the website. Eleven of these were 
general resource requests, e.g. 'more videos', and the other 6 were more topic specific. Four of these 6 respondents were final year, e.g., 'If they contained lots of worked examples and notes on courses similar to ours.' (4th Science), 'Specific module content, almost like tutorials.' (4th Science).

Ten of the 34 comments were related to advertisement, focussing on what methods we should use to communicate about the website to students and what detail to include, e.g. 'More emphasis/encouragement from lecturers and tutors in the MSC.' and 'emails or reminders about topics being on them when covered in lectures'. Two further comments could also be considered as advertisement because they referred to the lack of resources or material that are in fact already on the MSC website, e.g. "Maybe online videos like Khan Academy cause they are very handy to follow worked solutions cause just reading a solution you can get lost if it's something you struggle with to begin with...". There were two comments on the interface (a more modern layout of the website), two on accessing resources if they needed help, and one final comment referred to the fact that the student would start using the resources now that they were aware of them due to the survey.

\subsubsection{Students who have used the MSC website and the MSC online resources ( $n=30$ )}

Respondents who have used the MSC website and MSC online resources were given fixed options on how often they used the online resources (Q8), 'at least once a day' (1), at least once a week (7), 'at least once a month' (14), and 'at least once a semester' (8). Asked (Q9) about the ease of finding suitable resources, the fixed options selected were 'very easy' (4), 'easy' (16), 'neither easy or nor difficult' (9), and 'difficult' (1). When asked to rate these online resources (Q10), 11 and 16 respondents selected very good and good respectively. The remaining three selected neutral. Asked how likely they were to use the resources and links on the MSC website instead of those from another source or website (Q11), respondents selected 'More Likely' (19), 'Neither likely nor unlikely' (9), 'Less Likely' (2). Question 12 was optional and asked for lists of topics or resources respondents would like added to the website, there were three responses. One listed a third-year module which doesn't currently have online resources; the other two mentioned resources that they found had worked for them, e.g. quizzes and videos "I used a link once which was a quiz. When you got an answer wrong it showed you how to do it correctly, more of them maybe?"

Finally, in this section of the survey, there was an open question (Q13) asking for suggestions on how we might improve the MSC website, 27 (of 30) responses were relevant. Nine comments related to the structure or user interface of the website. Six of these nine were suggestions on modernising the website, e.g. 'Update it. More modern and user friendly'. Three of the nine, all from 3rd Science and two of whom used the website at least once a week, were happy with the current design, e.g. 'It's very easy to navigate, I'm happy with it'.

Another nine (of 27) relevant comments related specifically to the content of the MSC website, these were from 3rd years and one 4th year student. Six were general suggestions for more content and more topic specific content, the other three comments specifically requested that MSC workshop notes be left on the website for longer, e.g. "Workshop notes should be left online and not removed following the workshops."

Seven respondents stated that they had no suggestions, and five of these had indicated in Q9 that it was easy or very easy to find resources on the website. The remaining two comments, both from 1 st year Science students, stated that they were happy with the website. It was not clear if they were referring to the structure or content, or both.

\subsection{Communications about the MSC website ( $n=99)$}

All survey respondents ( $n=99$ ) were given (Q14) fixed options on the best way for the MSC to communicate about its website and online resources. They selected: Email (65); Message on the module VLE class forum (58); Announcement in lectures (62); Facebook and Twitter (27). No 
students selected 'I do not want to receive these communications'. The 214 responses included two who selected the 'other' open option. One respondent, who had also selected the email and VLE forum options, commented 'Email with a link, because students are actually that lazy'. The second student, who had also selected all the fixed options, added 'Maybe posters in the MSC walls and door as you walk in, leaflets with specifics about MSC'.

\section{Discussion, conclusion and future work}

This was a short local survey of limited scope, with a small number of respondents, all of whom used the MSC drop-in. However, it does provide an interesting 'first look' at students' engagement with an MSC website. We are now reconsidering our advertisement of the website, particularly with early year students. To this end, we are automatically including a website link in all communications. Tutors have been instructed to remind students of the website and how to use it, and the website is open and displayed on our screens during drop-in sessions. All but one respondent indicated that they used the website to find practical MSC information, which was its original purpose, and the majority of early year users were happy with the resources provided. A small number of website users and non-users stated a preference for face-to-face support, which is consistent with findings in our staff survey (Mac an Bhaird et al., in preparation). Indeed, when we first expanded the provision of topic specific resources for 1 st and 2 nd years, it had been in an effort to provide extra reliable online support for 'at-risk' students who were not getting as much one-to-one attention in our drop-in due to overcrowding.

Some responses referred to the lack of institutional information and training received on the use of technology, and the lack of guidance on how to use the website. Online web searches for topic specific questions can lead to unmoderated sites where information is often wrong or misleading (Kiili et al., 2008). Analysis of our extra questions, to be reported on elsewhere, indicate that 23 of 59 respondents always think about the reliability of online resources before they use them, 33 sometimes and three never. Goldman et al. (2012) found that when sourcing information on the internet, 'better students' were more readily able to identify reliable sites than 'poorer' students. Therefore, it could be argued that MSCs have an important role to play in the provision of appropriate online resources, especially as Henderson et al. (2015, p.1577) state that, "....students' uses of digital technologies (and perceptions of 'what works' best) are clearly being shaped by the university contexts within which students are situated..."

However, some of the early year student responses indicated that they wanted a more precise breakdown of resources to match the weekly demands of their courses, and students of more advanced modules identified the lack of resources for their modules as an issue. These responses have caused us to reassess the MSC's role in providing this level of online support for students, in addition to reviewing where the divide lies between lecturer and MSC responsibility. We recommend that practitioners considering the expansion of resource provision on their MSC website contemplate this issue.

\section{References}

Berry, E., Mac an Bhaird, C. and O'Shea, A., 2015. Investigating relationships between the usage of Mathematics Learning Support and performance of at-risk students. Teaching Mathematics and its Applications, 34, pp.194-204, https://doi.org/10.1093/teamat/hrv005

Goldman, S.R., Braasch, J.L.G., Wiley, J., Graesser, A.C. and Brodowinska, K., 2012. Comprehending and Learning from Internet Sources: Processing Patterns of Better and Poorer Learners. Reading Research Quarterly, 47(4), pp.356-381, https://doi.org/10.1002/RRQ.027 
Grove, M.J., Guiry, S. and Croft, A.C., 2019. Specialist and more-able mathematics students: understanding their engagement with mathematics support. International Journal of Mathematical Education in Science and Technology, https://doi.org/10.1080/0020739X.2019.1603407

Henderson, M., Selwyn, N. and Aston, R., 2017. What works and why? Student perceptions of 'useful' digital technology in university teaching and learning. Studies in Higher Education, 42(8), pp.1567-1579, https://doi.org/10.1080/03075079.2015.1007946

Kiili, C., Laurinen, L. and Marttunen, M., 2008. Students evaluating Internet sources - From versatile evaluators to uncritical readers. Journal of Educational Computing Research, 39(1), pp.75-95, https://doi.org/10.2190/EC.39.1.e

Lawson, D.A., Croft, A.C. and Halpin, M., 2003. Good Practice in the Provision of Mathematics Support Centres (2nd edn.). Birmingham, UK: LTSN Maths, Stats and OR Network. Available via http://www.mathcentre.ac.uk/resources/guides/goodpractice2E.pdf [Accessed 10 January 2020].

Lawson D. A., Croft, T. A. and Waller, D., 2012. Mathematics support past, present and future. In Centre for Engineering and Design Education (Eds.), Proceedings of EE 2012 - International Conference on Innovation, Practice and Research in Engineering Education, Conference Proceedings. Loughborough, Leicestershire, England: Loughborough University. ISBN: 9781 90763216 7. Available via http://cede.lboro.ac.uk/ee2012/papers/ee2012 submission 179 gp.pdf [Accessed 10 January 2020].

Mac an Bhaird, C. and Lawson, D.A., 2012. How to set up a mathematics and statistics support provision. sigma Coventry: Coventry University. Available via http://www.sigma-network.ac.uk/wpcontent/uploads/2012/11/51691-How-to-set-up...final .pdf [Accessed 10 January 2020].

Mac an Bhaird, C., Morgan, T. and O'Shea, A., 2009. The impact of the mathematics support centre on the grades of first year students at the National University of Ireland Maynooth. Teaching Mathematics and its Applications, 28(3), pp.117-122, https://doi.org/10.1093/teamat/hrp014

Mac an Bhaird, C., Mulligan, P. and O'Malley, J., 2020a. Mathematics support centre attendees and their use of online resources. MSOR Connections, 18(3), pp.63-69

Mac an Bhaird, C., Mulligan, P. and O'Malley, J. (in preparation). Mathematics Support Centre Websites: Provision in Ireland and the UK in 2018.

Matthews, J., Croft, T., Lawson, D. and Waller, D., 2013. Evaluation of mathematics support centres: a literature review. Teaching Mathematics and its Applications, 32(4), pp.173-190, https://doi.org/10.1093/teamat/hrt013

O'Sullivan, C., Mac an Bhaird, C., Fitzmaurice, O. and Ní Fhloinn, E., 2014. An Irish Mathematics Learning Support Network (IMLSN) report on student evaluation of mathematics learning support: insights from a large-scale multi-institutional survey. National Centre for Excellence in Mathematics and Science Teaching and Learning (NCE-MSTL), University of Limerick, Republic of Ireland. Available via http://mural.maynoothuniversity.ie/6890/1/CMAB IMLSNFinalReport.pdf [Accessed 10 January 2020]. 